\title{
Food consumption patterns in an adult urban population in Beirut, Lebanon
}

\author{
Lara Nasreddine ${ }^{1,2}$, Nahla Hwalla ${ }^{3, *}$, Abla Sibai ${ }^{4}$,Mouïn Hamzé ${ }^{1}$ and Dominique \\ Parent-Massin ${ }^{2}$ \\ 'Lebanese Council for Scientific Research, BP 11-8281, Beirut, Lebanon: '2aboratoire de Toxicologie Alimentaire, \\ ESMISAB/UBO, Technopole Brest-Iroise, F-29280 Plouzane, France: ${ }^{3}$ Department of Nutrition and Food Science, \\ Faculty of Agriculture and Food Sciences, American University of Beirut, PO Box 11-0236, Riad El Solh, Beirut \\ 1 107-2020, Lebanon: ${ }^{4}$ Department of Epidemiology and Population Health, Faculty of Health Sciences, American \\ University of Beirut, Lebanon
}

\section{Submitted 20 July 2004: Accepted 18 January 2005}

\begin{abstract}
Objectives: To investigate, measure and assess the food consumption pattern of the adult population living in Beirut, Lebanon, and to identify inadequate or excessive intake of food groups particularly linked to non-communicable diseases.

Design: A cross-sectional food consumption survey was conducted in 2001. Dietary habits were assessed by means of a quantitative food-frequency questionnaire.

Setting: Dietary survey of the urban population (Beirut).

Subjects: Random sample of 444 adult subjects (aged 25-54 years) in Beirut.

Results: The mean consumption of food by the study population was estimated to be $3030 \mathrm{~g} \mathrm{day}^{-1}$, providing an energy intake of $2523.57 \mathrm{kcal} \mathrm{day}^{-1}$. Fat contributed $38.9 \%$ to the average daily energy intake, protein $13.4 \%$ and carbohydrates $47.2 \%$. Mean consumption of fruits and vegetables was approximately $367 \mathrm{~g} \mathrm{day}^{-1}$ and $45.3 \%$ of subjects consumed less than the recommended $400 \mathrm{~g}$ daily. Cereals contributed $324.5 \mathrm{~g} \mathrm{day}^{-1}$, providing $35.0 \%$ of daily energy intake, with bread being the most highly consumed $\left(146.2 \mathrm{~g} \mathrm{day}^{-1}\right)$ in this food group. The mean intake of meat and poultry products was $91.7 \mathrm{~g} \mathrm{day}^{-1}$ and provided $8.8 \%$ of daily energy intake, with consumption of butchery products especially beef being the highest $\left(47.6 \mathrm{~g} \mathrm{day}^{-1}\right)$ followed by poultry $\left(36.1 \mathrm{~g} \mathrm{day}^{-1}\right)$. A low consumption of fish was noted $\left(19.7 \mathrm{~g} \mathrm{day}^{-1}\right)$, with $73.6 \%$ of subjects consuming less than the recommended 2 servings of fish per week. Dairy products contributed $243.1 \mathrm{~g} \mathrm{day}^{-1}$ or $10.9 \%$ of daily energy intake, and milk was the least consumed dairy product ( $56.8 \%$ of consumers). The intake of added fats and oils, excluding those in cooked recipes, was $20.4 \mathrm{~g} \mathrm{day}^{-1}$; olive oil was not used in cooking but was added solely at the table and its mean intake was $5 \mathrm{~g} \mathrm{day}^{-1}$. The consumption of butter was low $\left(0.86 \mathrm{~g} \mathrm{day}^{-1}\right)$ and vegetable oil was the type of fat mostly used in cooking. The average intake of alcoholic beverages was low $\left(33.6 \mathrm{~g} \mathrm{day}^{-1}\right.$ ), accounting for $0.7 \%$ of total energy intake. Women had significantly higher intakes of milk, dairy products, vegetables and coffee than men $(P<0.05)$. The percentage of women who reported the use of low-fat items was significantly higher than that of men. Younger people (25-34 years) ate significantly more meat, sugar, alcoholic beverages and soft drinks, and consumed significantly less cooked vegetables and legumes, than older ones $(P<0.05)$.

Conclusions: The rather high contribution of fat to daily energy intake, the low intake of fish and the relatively high percentage of people consuming less than the recommended amount of fruits and vegetables observed in this study suggest that the adult Lebanese population is at increased risk of cardiovascular diseases, obesity and other non-communicable diseases, which provides the basis for recommending increased intakes of fish, particularly fatty fish, and fruits and vegetables.
\end{abstract}

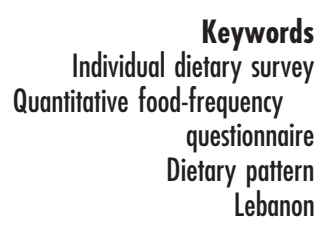

Food consumption patterns and intakes of selected nutrients and phytochemicals have been associated with the incidence of non-communicable diseases (NCDs) in both developed and developing countries. Food as consumed contains naturally - intentionally or unintentionally - many different chemicals that are either desirable (such as micronutrients or phytochemicals) or undesirable (such as natural toxins), or excessive amounts of otherwise desired components (including nutrients). A low intake of nutritionally important foods and a high 
exposure to hazardous chemicals in the diet may pose a serious public health risk. Also, in order to assess the risk of a population being exposed to inadequate levels of nutrients and undesirable chemicals in the diet, it is necessary to generate data on the types and amounts of foods typically consumed in that population ${ }^{1}$.

There are three main approaches that may be used for obtaining food consumption data: food-supply surveys, household consumption surveys and individual dietary intake surveys ${ }^{2,3}$. Food-supply surveys, also known as food balance sheets (FBSs), provide gross annual estimates of the national availability of food commodities. They are usually based on national food production, imports, exports, and agricultural and industrial use. Household survey data can be obtained by a variety of methods such as food record, inventory and list recall. Household surveys provide more reliable data than foodsupply surveys but their value remains limited compared with individual food intake data ${ }^{1,2}$. Surveys of food intake by individuals can be conducted by five main methods: $24-$ hour dietary recalls, food records, duplicate diet portion, dietary history and food-frequency questionnaires (FFQs) ${ }^{1-5}$. The importance of individual dietary surveys resides in identifying the association between an individual's dietary pattern over a period of time and the associated phenomena that can result from that particular dietary behaviour.

In Lebanon, a Mediterranean country with a territory of $10452 \mathrm{~km}^{2}$ and an estimated population of about 4 million, $40 \%$ of the population lives in the capital Beirut, which is considered the melting pot of the country. The last comprehensive dietary study in Lebanon was conducted in 1961 by the Interdepartmental Committee on Nutrition for National Defense ${ }^{6}$. Afterwards studies on the dietary habits of the Lebanese population were only sparsely described in the scientific literature. Dietary research based on individual surveys has been lacking in continuity, and the few research projects have been representative of only small population groups and restricted to specific regions ${ }^{7-11}$, and thus should be interpreted with caution. At present, two major sources of data are available for assessment of the food consumption pattern in Lebanon. First, the
Food and Agriculture Organization (FAO) has compiled agricultural production and food availability data for countries of the Near East ${ }^{12}$, which can be used in Lebanon. Second, a household budget survey (HBS) was realised in 1997 in Beirut and its suburbs by the Lebanese Central Administration for Statistics ${ }^{13}$, providing economic as well as food consumption data. Because the data provided by both the HBS and FBSs represent food availability rather than actual food consumption data, there is a need to realise individual dietary intake surveys in Lebanon - and hence the significance of the present investigation.

In the present study, an individual dietary intake survey was conducted to investigate, measure and assess the food consumption pattern of the adult population living in Beirut and to identify inadequate or excessive intake of specific food groups particularly linked to NCDs. This dietary study constitutes a preliminary investigation of a broader risk assessment study aimed at evaluating the exposure of the above-mentioned population group to contaminants through the diet.

\section{Subjects and methods}

\section{Sample characteristics}

A cross-sectional dietary survey was carried out in a random sample of the adult population living in Beirut and its suburbs. In the absence of a sampling frame for the country, the area surveyed was stratified into nine units based on the administrative classification of the city and its suburbs. Within each unit, an equal number of households $(n=65)$ was selected randomly yielding a sample of 590 households. A short screening instrument was developed for all household members, the objective of which was to exclude from the target population ethnic minorities, refugees, pregnant and lactating women, people following restrictive diets (e.g. vegetarians) and people with chronic diseases including diabetes, renal failure and cardiovascular diseases. Within each household one adult subject aged 25-54 years was invited to participate. Recruitment efforts targeted a sample with an age and sex distribution proportionate to that of the baseline population according to the $\operatorname{HBS}^{13}$ (Table 1).

Table 1 Age and sex characteristics of the study sample compared with the distribution of the baseline population aged $25-54$ years in Beirut ${ }^{13}$

\begin{tabular}{|c|c|c|c|c|c|c|c|c|c|}
\hline \multirow[b]{3}{*}{ Age (years) } & \multicolumn{3}{|c|}{ Men } & \multicolumn{3}{|c|}{ Women } & \multicolumn{3}{|c|}{ Total } \\
\hline & \multirow{2}{*}{$\frac{\text { Baseline }}{\%}$} & \multicolumn{2}{|c|}{ Study sample } & \multirow{2}{*}{$\frac{\text { Baseline }}{\%}$} & \multicolumn{2}{|c|}{ Study sample } & \multirow{2}{*}{$\frac{\text { Baseline }}{\%}$} & \multicolumn{2}{|c|}{ Study sample } \\
\hline & & $n$ & $\%$ & & $n$ & $\%$ & & $n$ & $\%$ \\
\hline $25-34$ & 43.7 & 84 & 40.0 & 40.3 & 91 & 38.9 & 41.9 & 175 & 39.5 \\
\hline $35-44$ & 30.4 & 67 & 31.9 & 33.5 & 78 & 33.3 & 32.1 & 145 & 32.6 \\
\hline $45-54$ & 25.9 & 59 & 28.0 & 26.1 & 65 & 27.7 & 26.0 & 124 & 27.9 \\
\hline Total & 100 & 210 & 100 & 100 & 234 & 100 & 100 & 444 & 100 \\
\hline
\end{tabular}




\section{Food consumption and dietary assessment method} Food consumption data were obtained using a questionnaire which included, in addition to personal data and indicators of socio-economic level (education, occupation, family and household information), measurements of weight $(\mathrm{kg})$ and height $(\mathrm{cm})$, and use of dietary supplements.

The survey took place between April and September 2001. The subjects were interviewed at home after obtaining their consent. The eligibility of the subject was verified and then the questionnaire was administered. The interview typically lasted an hour. The person responsible for data collection was a research dietitian trained in the methodology to be used before the start of the fieldwork.

Dietary habits were assessed by means of a quantitative food-frequency questionnaire (QFFQ), which was designed to estimate food intake over the past year. It consisted of a list of 112 food items as normally consumed and included a number of composite dishes that may contain multiple ingredients. The foods and beverages were also categorised into 16 groups.

A reference portion, expressed in household measures or grams, was specified for each food item in the QFFQ. The individual was asked to estimate the number of times per day, week, month or year he/she consumed this particular food product and the amount usually eaten per food item by making comparisons with the specified reference portion. Common household measures, measuring cups, spoons and a ruler were shown to assist the individual in the estimation process.

\section{Data analysis}

A database application using Microsoft ${ }^{\circledR}$ Access (Microsoft Corp., Redmond, WA, USA) was developed specifically for the objectives of the study. The devised analysis module permitted to group food items into 16 categories and to determine mean consumption values per food item and per food group $\left(\mathrm{g} \mathrm{day}^{-1}\right)$, average daily intake per individual, per sex group $\left(\mathrm{g} \mathrm{day}^{-1}\right.$ ) and per age group $\left(\mathrm{g} \mathrm{day}^{-1}\right)$, and the percentage of consumers per food item and per food group.

Nutritionist Pro software, version 1.2, was then used to estimate the intakes of energy and macronutrients ${ }^{14}$. In order to estimate the energy and macronutrient values of traditional food items not included in the abovementioned database, recipes were added based on a local cookbook ${ }^{15}$. Composite dishes were analysed as normally consumed, i.e. without extracting added oil, fat or other ingredients from the recipes. Energy, proteins, fat and carbohydrates per gram were calculated for each food item on the QFFQ list. Individual daily energy intake was then computed by summation of the respective products of the quantity consumed and the energy per gram value for each food item ${ }^{16}$. The same procedure was used to determine the daily intake of each macronutrient ${ }^{17}$.
All subsequent statistical analyses were performed using SPSS version 11 (SPSS Inc., Chicago, IL, USA). The analyses were conducted stratified by age and gender whenever appropriate. Student's $t$-test and analysis of variance were performed to compare the group means. A $P$-value $<0.05$ was considered significant.

\section{Results}

Out of a total of 590 subjects contacted, the survey population consisted, at the end of the study, of 444 individuals; 210 were men (47.3\%) and 234 were women (52.7\%). The refusal rate (24.7\%) was higher among men (29\%) than women (19\%). The sample's age and sex distribution was similar to the baseline population aged 25-54 years in Beirut as determined by the HBS ${ }^{13}$ (Table 1 ).

Mean estimates $\left(\mathrm{g}\right.$ person ${ }^{-1} \mathrm{day}^{-1}$ ) of daily intake per food item and the percentage contribution of each food item to the average daily intake (on a weight basis) of individuals aged 25-54 years were calculated. Total weight of the daily ration (average daily intake), as estimated by adding the respective mean estimates of all food items, was found to be $3030 \mathrm{~g} \mathrm{day}^{-1}$ including beverages and $1335 \mathrm{~g} \mathrm{day}^{-1}$ excluding beverages.

Based on the calculated values of energy, protein, fat and carbohydrates per gram for each food item, the mean ( \pm standard deviation) energy provided by the daily ration was estimated to be $2523.57 \pm 763.98 \mathrm{kcal} \mathrm{person}^{-1} \mathrm{day}^{-1}$. Of daily calories, $13.4 \%$ were supplied by proteins, $38.9 \%$ by fat and $47.2 \%$ by carbohydrates. The energy density of the diet was determined to be $0.83 \mathrm{kcalg}^{-1}$, while the energy density excluding beverages was $1.76 \mathrm{kcal} \mathrm{g}^{-1}$.

The mean consumption value for each of the 16 food groups and the contribution of each food group to daily energy intake are shown in Table 2.

Bread, cereals and cereal-based products together contributed $324.5 \mathrm{~g} \mathrm{day}^{-1}$ and provided $35.0 \%$ of total energy intake. The subgroup 'bread and toast' was the most frequently and the most highly consumed item $\left(146.2 \mathrm{~g} \mathrm{day}^{-1}\right)$ in this food group, providing $16.1 \%$ of the daily energy intake, while all other cereals and cereal products combined provided $18.9 \%$ of daily energy intake.

The average intake of sugar and sugar derivatives such as jam, chocolate, honey, etc. was $33.9 \mathrm{~g} \mathrm{day}^{-1}$ and contributed $6.0 \%$ to total energy intake. The average intake of soft drinks and pre-packed juices was $242.1 \mathrm{~g} \mathrm{day}^{-1}$ contributing $4.5 \%$ to total energy intake. Free sugar, defined by the World Health Organization (WHO) $)^{18}$ as being 'all mono- and disaccharides added to foods by manufacturer, cook or consumer, plus sugars naturally present in honey, syrups and fruit juices', was found to contribute $11.4 \%$ to daily energy intake, which is higher than the recommended maximum value of $10 \%{ }^{18}$.

The average intake of fruits was of $220.5 \mathrm{~g} \mathrm{day}^{-1}$ and the mean intake of fresh fruit juices was $65 \mathrm{~g} \mathrm{day}^{-1}$. Fruits and fruit juices contributed $6.7 \%$ to daily energy intake. The 
Table 2 Mean consumption values and contribution of each food group to energy intake in the total study population aged $25-54$ years $(n=444)$, Beirut, Lebanon

\begin{tabular}{lcc}
\hline Food group & Consumption $\left(\mathrm{g} \mathrm{day}^{-1}\right)$ & $\begin{array}{c}\text { Contribution to energy } \\
\text { intake }(\%)\end{array}$ \\
\hline Meat and poultry & $91.7 \pm 44.6(87.6-95.9)$ & 8.8 \\
Fish & $19.7 \pm 17.3(18.1-21.3)$ & 1.0 \\
Eggs & $12.1 \pm 13.6(10.9-13.4)$ & 0.7 \\
Milk and dairy products & $243.1 \pm 141.2(229.9-256.2)$ & 10.9 \\
Vegetables raw & $146.5 \pm 66.0(140.4-152.7)$ & 2.3 \\
Vegetable-based dishes & $98.9 \pm 48.4(94.4-103.4)$ & 3.2 \\
Potato and potato-based products & $63.5 \pm 37.5(60.0-67.0)$ & 6.5 \\
Fruits and fruit juices* & $285.5 \pm 110.7(275.2-295.9)$ & 6.7 \\
Pulses, nuts and seeds & $52.4 \pm 30.1(49.6-55.2)$ & 5.6 \\
Cereals and cereal-based products & $178.3 \pm 91.2(169.8-186.8)$ & 18.9 \\
Bread and toast & $146.2 \pm 65.8(140.1-152.4)$ & 16.1 \\
Fats and oils added at table† & $20.4 \pm 8.4(19.6-21.7)$ & 6.8 \\
Sugar and sugar derivatives & $33.9 \pm 29.6(31.2-36.7)$ & 6.0 \\
Sodas and pre-packed juices & $242.1 \pm 216.7(221.9-262.3)$ & 4.5 \\
Caffeinated beverages & $213.7 \pm 164.1(198.4-229.0)$ & 0.17 \\
Alcoholic beverages & $33.6 \pm 70.9(27.0-40.2)$ & 0.7 \\
\hline
\end{tabular}

Consumption values are mean \pm standard deviation ( $95 \%$ confidence interval).

${ }^{*}$ Fruit juices contribute $65 \mathrm{~g}$ to the total value of $285.5 \mathrm{~g}$ daily.

†The values are for table-added fats and oils such as butter, mayonnaise, sesame paste and olive oil, as well as fats and oils used in frying. It excludes fats and oils consumed with cooked dishes and other composite products.

fruit varieties consumed most widely by the population group included citrus fruits $\left(75.3 \mathrm{~g} \mathrm{day}^{-1}\right)$, apples $\left(61 \mathrm{~g} \mathrm{day}^{-1}\right)$, bananas $\left(20.7 \mathrm{~g} \mathrm{day}^{-1}\right)$ and watermelon $\left(15 \mathrm{~g} \mathrm{day}^{-1}\right)$.

The mean consumption value for raw vegetables was $146.5 \mathrm{~g} \mathrm{day}^{-1}$ and contributed $2.3 \%$ to energy intake. Cooked vegetables were mostly eaten as stews, and their consumption is reported under vegetable-based dishes although these may contain other secondary ingredients such as rice or oil. The mean consumption level of cooked vegetables was $98.9 \mathrm{gday}^{-1}$, providing $3.2 \%$ of daily energy intake.

The mean consumption of fresh fruits and vegetables combined was estimated to be $367 \mathrm{~g} \mathrm{day}^{-1}$ and $45.3 \%$ of the study subjects consumed less than the FAO/WHO recommended value of $400 \mathrm{~g}$ of fruits and vegetables per day ${ }^{18}$.

The mean intake of meat and poultry products was $91.7 \mathrm{~g} \mathrm{day}^{-1}$ and provided $8.8 \%$ of daily energy intake. Within the meat group, the consumption of butchery products was the highest $\left(47.6 \mathrm{~g} \mathrm{day}^{-1}\right)$, followed by poultry $\left(36.1 \mathrm{~g} \mathrm{day}^{-1}\right)$. Among butchery products, beef was consumed much more $(60.7 \%$ of consumers) than lamb (27.8\% of consumers), while $11.5 \%$ consumed beef and lamb interchangeably. A low consumption of fish was noted with an average value of $19.7 \mathrm{~g} \mathrm{day}^{-1} ; 73.6 \%$ of subjects were found to consume less than 2 servings of fish per week and 64.6\% less than 1 serving per week. Overall, meat, fish and eggs supplied $123.5 \mathrm{~g} \mathrm{day}^{-1}$, which contributed $35.0 \%$ of the daily protein intake.

Milk and dairy products contributed $243.1 \mathrm{gday}^{-1}$, providing $10.9 \%$ of daily energy intake. In the population group, yoghurt was the most consumed dairy product $\left(68.3 \mathrm{~g} \mathrm{day}^{-1}\right)$, followed by cheese $\left(35.1 \mathrm{~g} \mathrm{day}^{-1}\right)$ and then by lebneh $\left(27.8 \mathrm{~g} \mathrm{day}^{-1}\right)$, a traditional dairy product.
Among dairy products milk was the least consumed by the population group, with $43.2 \%$ of subjects reporting not drinking milk. When dairy products, meat, fish and eggs were added, they contributed $56.0 \%$ of the daily protein intake.

The mean intake estimate for added fats and oils (excluding those used in cooking) was $20.4 \mathrm{~g} \mathrm{day}^{-1}$, giving $6.8 \%$ of daily energy intake. Olive oil was not used in cooking but was solely added to salads and other traditional dishes, and its daily intake was $5 \mathrm{~g}$. The consumption of butter was low ( $42.6 \%$ of consumers), estimated as $0.86 \mathrm{~g} \mathrm{day}^{-1}$. The daily intake of fats and oils used in the frying of certain foods was estimated to be $4.86 \mathrm{~g} \mathrm{day}^{-1}$. Fats and oils used in the cooking of dishes were treated as an inherent part of the recipes. The type of fat mostly used in the cooking or frying of foods was vegetable oil (60\% of subjects), while $27 \%$ of subjects used both ghee and vegetable oil interchangeably and $0.2 \%$ used only ghee. Added fats and oils (excluding fats and oils used in the cooking of dishes) had the highest contribution to total fat intake, providing $16.9 \%$ of the daily fat intake. Milk and dairy products contributed $15.6 \%$ of daily fat intake whereas meat and poultry products provided $13.2 \%$.

The average intake of alcoholic beverages was $33.6 \mathrm{~g} \mathrm{day}^{-1}$, which accounted for $0.7 \%$ of total energy intake. Beer was the most widely consumed alcoholic beverage (33.8\% of consumers), followed by wine (25\%) and then by other types of alcohol (19.4\%).

Gender differences in mean consumption (g person $^{-1}$ $\mathrm{day}^{-1}$ ) and the contribution of food groups to daily energy intake are described in Table 3. Mean consumption values $\left(\mathrm{g} \mathrm{day}^{-1}\right.$ ) of bread and toast, cereal and cereal products, eggs, meat and poultry, potatoes, pulses, nuts and seeds, sugar and sugar derivatives, added fats and oils, alcoholic 


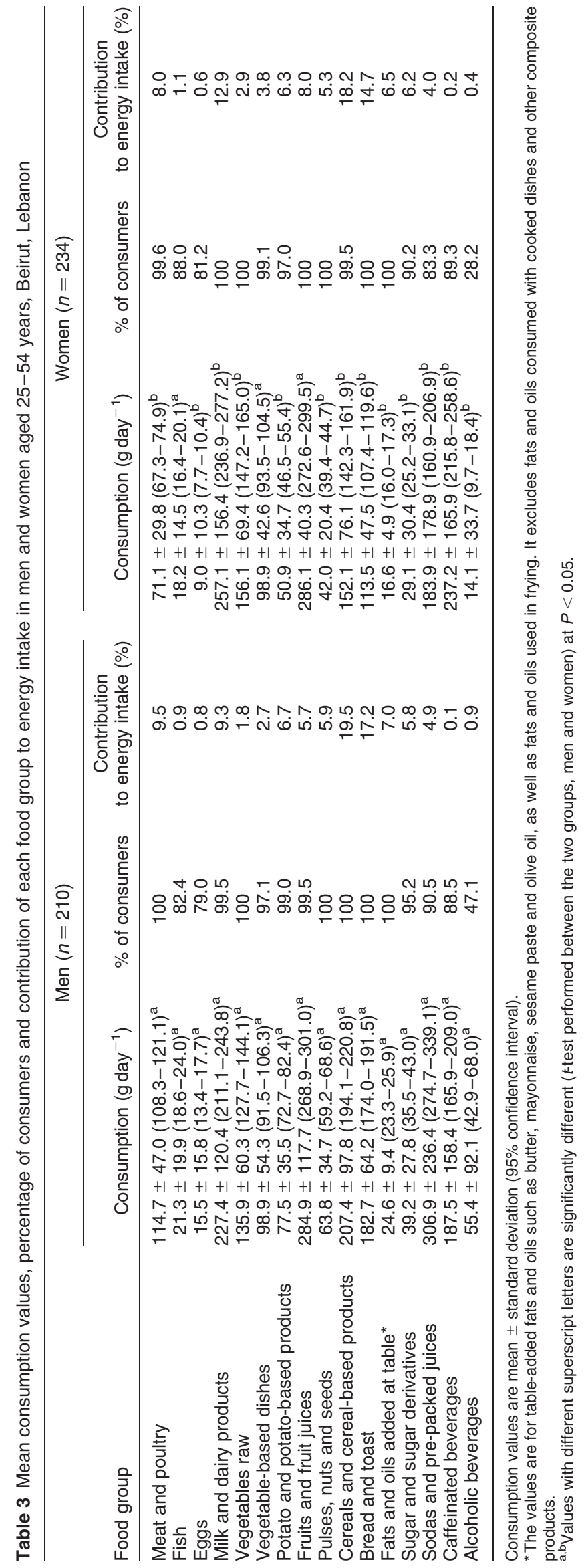


beverages and soft drinks were significantly higher in men than women $(P<0.05)$. However, intakes of milk and dairy products, vegetables and coffee were significantly higher in women. The daily intake of fruits in grams did not differ significantly between men and women, but the mean contribution of fruits to daily energy intake was higher among women (8.0\%) compared with men (5.7\%). The percentage of women who reported the use of low-fat items was higher than the percentage of men: low-fat milk ( $48.6 \%$ of women vs. $17.0 \%$ of men); other dairy products (38.5\% of women vs. $7.2 \%$ of men); other low-fat items ( $40.4 \%$ of women vs. $14.3 \%$ of men). Intake of fish did not differ significantly between genders.

The mean consumption values of the various food groups by age are shown in Table 4 for men and Table 5 for women. Younger men (25-34 years) consumed significantly more meat and poultry, potato and potato-based products, cereals and cereal-based products, sugar and sugar derivatives, soft drinks and pre-packed juices compared with one or both of the two older age groups $(P<0.05)$. Similarly, the intake of alcoholic beverages by men aged 25-34 years was significantly higher than by men aged 45-54 years. On the other hand, the younger men (25-34 years) consumed significantly less pulses than men aged 35-44 years and significantly less cooked vegetables and caffeinated beverages than the two other age groups (35-44 and 45-54 years). Younger women (25-34 years) consumed significantly more meat and poultry, cereals and cereal-based products, sugar and sugar derivatives and soft drinks and pre-packed juices than women aged 45-54 years. On the other hand, younger women (25-54 years) consumed significantly less cooked vegetables than those aged 45-54 years and significantly less coffee than the two older age groups (35-44 and 45-54 years). For both genders, the consumption of meat and poultry, potatoes, sugar derivatives and soft drinks decreased significantly with age, while the consumption of caffeinated beverages increased significantly. Men aged 25-34 years had the highest energy intake with an average of $3187.3 \mathrm{kcal} \mathrm{day}^{-1}$.

\section{Discussion}

The present study is the first to describe the eating pattern among Lebanese adults in terms of quantities and types of foods most commonly consumed. The FFQ method, which was used in this study, has been reported to provide a relatively simple and effective way of gathering individual data on food consumption and was found to be adaptable and appropriate for use in assessing the usual intake and dietary patterns in a certain population $^{19,20}$. The time required to administer the questionnaire was found to be less than other surveys; the questionnaire was administered in a standardised form and therefore allowed easy analysis of food consumption patterns ${ }^{20}$. Most importantly, the main advantage of FFQs may be that they are capable of capturing data that go beyond the time limits of conventional dietary surveys ${ }^{20}$. However, total food intake cannot be readily estimated from a classic FFQ, which asks respondents to indicate only the frequency of consumption of a list of food items and is used for qualitative dietary assessment. In order to quantify food intake, questionnaires that include information on serving sizes as well as on the frequency of consumption have been developed and are referred to as quantitative food-frequency questionnaires (QFFQs) ${ }^{17}$.

The present study showed that the mean consumption of fresh fruits and vegetables was $367 \mathrm{~g} \mathrm{person}^{-1}$ day $^{-1}$, thus approaching the WHO/FAO minimum recommended

Table 4 Mean consumption of food groups by age in men $(n=210)$, Beirut, Lebanon

\begin{tabular}{lccc}
\hline & \multicolumn{3}{c}{ Consumption $\left(\mathrm{g}\right.$ day $\left.{ }^{-1}\right)$} \\
\cline { 2 - 4 } Food group & $25-34$ years & $35-44$ years & $45-54$ years \\
\hline Meat and poultry & $131.8 \pm 48.6(121.3-142.3)^{\mathrm{a}}$ & $112.9 \pm 44.4(101.9-123.8)^{\mathrm{b}}$ & $92.8 \pm 37.7(83.1-102.6)^{\mathrm{c}}$ \\
Fish & $19.2 \pm 15.9(15.7-2.6)^{\mathrm{a}}$ & $27.3 \pm 26.3(20.8-33.8)^{\mathrm{a}}$ & $17.6 \pm 14.9(13.8-21.5)^{\mathrm{b}}$ \\
Eggs & $13.8 \pm 14.0(10.7-16.8)^{\mathrm{a}}$ & $15.0 \pm 15.8(11.14-18.9)^{\mathrm{a}}$ & $18.7 \pm 17.8(14.1-23.3)^{\mathrm{a}}$ \\
Milk and dairy products & $232.3 \pm 131.8(203.7-260.9)^{\mathrm{a}}$ & $213.0 \pm 106.1(186.9-239.1)^{\mathrm{a}}$ & $236.6 \pm 119.1(205.8-267.3)^{\mathrm{a}}$ \\
Vegetables raw $_{\text {Vegetable-based dishes }}$ & $133.8 \pm 59.9(120.8-146.8)^{\mathrm{a}}$ & $132.6 \pm 59.1(118.1-147.2)^{\mathrm{a}}$ & $142.5 \pm 62.6(126.3-158.7)^{\mathrm{a}}$ \\
Potato and potato-based products & $82.4 \pm 48.7(71.8-92.9)^{\mathrm{a}}$ & $101.9 \pm 57.1(87.8-115.9)^{\mathrm{b}}$ & $118.7 \pm 52.2(105.2-132.2)^{\mathrm{b}}$ \\
Fruits and fruit juices & $87.0 \pm 36.4(79.1-94.9)^{\mathrm{a}}$ & $75.6 \pm 39.4(65.9-85.3)^{\mathrm{a}, \mathrm{b}}$ & $66.4 \pm 25.2(59.9-72.9)^{\mathrm{b}}$ \\
Pulses, nuts and seeds & $291.1 \pm 113.5(266.4-315.7)^{\mathrm{a}}$ & $276.1 \pm 96.4(252.4-299.8)^{\mathrm{a}}$ & $286.2 \pm 143.6(249.1-323.2)^{\mathrm{a}}$ \\
Cereals and cereal-based products & $56.5 \pm 30.5(49.9-63.2)^{\mathrm{a}}$ & $73.5 \pm 45.4(62.3-84.6)^{\mathrm{a}, \mathrm{b}}$ & $63.6 \pm 22.3(57.8-69.4)^{\mathrm{b}}$ \\
Bread and toast & $237.4 \pm 118.7(211.6-263.1)^{\mathrm{a}}$ & $194.4 \pm 80.5(174.4-213.9)^{\mathrm{a}, \mathrm{b}}$ & $180.2 \pm 68.5(162.5-97.9)^{\mathrm{b}}$ \\
Sugar and sugar derivatives & $192.6 \pm 66.4(178.2-207.0)^{\mathrm{a}}$ & $185.1 \pm 71.9(167.4-202.7)^{\mathrm{a}, \mathrm{b}}$ & $166.2 \pm 47.8(153.9-178.6)^{\mathrm{b}}$ \\
Added fats and oils & $46.8 \pm 27.9(40.7-52.8)^{\mathrm{a}}$ & $36.5 \pm 25.6(30.2-42.8)^{\mathrm{a}, \mathrm{b}}$ & $31.7 \pm 27.9(24.5-38.9)^{\mathrm{b}}$ \\
Sodas and pre-packed juices & $25.0 \pm 8.9(23.1-26.9)^{\mathrm{a}}$ & $25.6 \pm 12.2(22.6-28.6)^{\mathrm{a}}$ & $22.9 \pm 5.9(21.4-24.4)^{\mathrm{a}}$ \\
Alcoholic beverages & $371.7 \pm 239.7(319.0-423.7)^{\mathrm{a}}$ & $337.2 \pm 245.9(276.7-397.6)^{\mathrm{b}}$ & $182.9 \pm 166.9(139.7-226.0)^{\mathrm{b}}$ \\
Caffeinated beverages & $70.4 \pm 111.1(46.3-94.5)^{\mathrm{k}}$ & $52.3 \pm 82.6(32.0-72.6)^{*}$ & $37.9 \pm 67.6(20.5-55.4)^{\mathrm{k}}$ \\
\hline
\end{tabular}

Consumption values are mean \pm standard deviation ( $95 \%$ confidence interval).

${ }^{*}$ Although analysis of variance (ANOVA) revealed borderline significance, the Duncan test showed a significant difference between the age groups $25-34$ and $45-54$ years.

${ }_{\mathrm{a}, \mathrm{b}, \mathrm{c}}$ Values with different superscript letters are significantly different (ANOVA followed by Duncan's test) at $P<0.05$. 
Table 5 Mean consumption of food groups by age in women $(n=234)$, Beirut, Lebanon

\begin{tabular}{lccc}
\hline & & Consumption $\left(\right.$ g day $\left.{ }^{-1}\right)$ & \\
\cline { 2 - 4 } Food group & $25-34$ years & $35-44$ years & $45-54$ years \\
\hline Meat and poultry & $76.9 \pm 32.6(70.1-83.7)^{\mathrm{a}}$ & $70.6 \pm 29.0(64.1-77.1)^{\mathrm{a}, \mathrm{b}}$ & $63.6 \pm 25.1(57.4-69.8)^{\mathrm{b}}$ \\
Fish & $18.5 \pm 13.4(15.7-21.2)^{\mathrm{a}}$ & $19.6 \pm 16.6(15.8-23.3)^{\mathrm{a}}$ & $16.4 \pm 13.5(13.0-19.7)^{\mathrm{a}}$ \\
Eggs & $8.7 \pm 8.6(6.9-10.5)^{\mathrm{a}}$ & $8.8 \pm 9.8(6.6-11.0)^{\mathrm{a}}$ & $9.9 \pm 12.9(6.7-13.1)^{\mathrm{a}}$ \\
Milk and dairy products & $264.8 \pm 167.5(229.9-299.7)^{\mathrm{a}}$ & $262.6 \pm 157.3(227.1-298.0)^{\mathrm{a}}$ & $239.7 \pm 139.4(205.2-274.2)^{\mathrm{a}}$ \\
Vegetables raw & $155.0 \pm 68.3(140.7-169.2)^{\mathrm{a}}$ & $153.5 \pm 65.1(138.8-168.2)^{\mathrm{a}}$ & $160.8 \pm 76.5(141.9-179.8)^{\mathrm{a}}$ \\
Vegetable-based dishes & $91.4 \pm 41.1(82.8-99.9)^{\mathrm{a}}$ & $99.9 \pm 44.1(90.0-109.8)^{\mathrm{a}, \mathrm{b}}$ & $108.5 \pm 41.4(98.2-118.8)^{\mathrm{b}}$ \\
Potato and potato-based products & $56.6 \pm 38.1(48.7-64.5)^{\mathrm{a}}$ & $50.7 \pm 32.2(43.0-58.4)^{\mathrm{a}}$ & $43.3 \pm 29.1(36.0-50.5)^{\mathrm{a}}$ \\
Fruits and fruit juices & $275.8 \pm 102.5(254.4-297.1)^{\mathrm{a}}$ & $285.5 \pm 99.8(263.0-308.0)^{\mathrm{a}}$ & $301.2 \pm 111.7(273.5-328.9)^{\mathrm{a}}$ \\
Pulses, nuts and seeds & $39.1 \pm 18.1(35.4-42.9)^{\mathrm{a}}$ & $42.7 \pm 19.9(38.2-47.2)^{\mathrm{a}}$ & $45.4 \pm 23.6(39.5-51.3)^{\mathrm{a}}$ \\
Cereals and cereal-based products & $174.4 \pm 87.6(156.2-192.7)^{\mathrm{a}}$ & $145.5 \pm 59.8(132.0-159.0)^{\mathrm{a}}$ & $128.6 \pm 68.5(111.7-145.6)^{\mathrm{b}}$ \\
Bread and toast & $112.8 \pm 49.1(102.5-123.0)^{\mathrm{a}}$ & $111.8 \pm 45.0(101.7-122.0)^{\mathrm{a}}$ & $116.6 \pm 48.7(104.5-128.6)^{\mathrm{a}}$ \\
Sugar and sugar derivatives & $37.0 \pm 29.0(31.0-43.0)^{\mathrm{a}}$ & $23.4 \pm 19.5(19.0-27.8)^{\mathrm{a}}$ & $25.1 \pm 39.9(15.2-35.0)^{\mathrm{b}}$ \\
Added fats and oils & $16.1 \pm 4.6(15.1-17.0)^{\mathrm{a}}$ & $16.2 \pm 5.0(15.1-17.4)^{\mathrm{a}}$ & $17.8 \pm 5.4(16.5-19.1)^{\mathrm{a}}$ \\
Sodas and pre-packed juices & $228.4 \pm 205.3(185.6-271.1)^{\mathrm{a}}$ & $163.1 \pm 166.9(125.4-200.7)^{\mathrm{a}}$ & $146.6 \pm 137.6(112.5-180.7)^{\mathrm{b}}$ \\
Alcoholic beverages & $15.9 \pm 32.2(9.2-22.7)^{\mathrm{a}}$ & $13.1 \pm 34.2(5.4-20.8)^{\mathrm{a}}$ & $12.7 \pm 35.6(3.8-21.5)^{\mathrm{a}}$ \\
Caffeinated beverages & $202.4 \pm 160.9(168.9-236.0)^{\mathrm{a}}$ & $255.9 \pm 176.2(216.2-295.6)^{\mathrm{b}}$ & $263.4 \pm 153.5(225.4-301.5)^{\mathrm{b}}$ \\
\hline
\end{tabular}

Consumption values are mean \pm standard deviation ( $95 \%$ confidence interval).

a,b Values with different superscript letters are significantly different (ANOVA followed by Duncan's test) at $P<0.05$.

value of $400 \mathrm{~g}$ daily ${ }^{18}$. The mean intake of fruits and vegetables as estimated by this study is relatively higher than the levels reported by the WHO for less developed countries $^{18}$. This could be due to the availability and accessibility of these products on the Lebanese market, their high national production and their relatively low cost, in addition to them being important ingredients of the traditional diet. However, it was observed that $45.3 \%$ of the study subjects consumed less than the recommended amount. There is convincing evidence that the consumption of a diet rich in fruits and vegetables is associated with a significantly lower risk of cardiovascular diseases, obesity, diabetes and certain types of cancer. The protective effects of these foods are probably mediated through numerous beneficial nutrients including antioxidants, vitamins, minerals, phytochemicals, fibre and plant protein ${ }^{18,21-23}$.

This study showed that the average consumption of fish (19.7 $\mathrm{g} \mathrm{day}^{-1}$ ) was lower than the recommended 2 servings $(180 \mathrm{~g})$ per week ${ }^{24}: 74 \%$ of the subjects were found to consume less than 2 servings of fish per week and 65\% less than 1 serving per week. Fish is a good source of protein and does not have the high saturated fat content of fatty meat products. In addition, fish is a good source of omega- 3 fatty acids, which have been found to have beneficial effects on cardiovascular diseases, diabetes and cancer. The mechanisms by which omega-3 fatty acids reduce NCDs are still under study. However, research has shown that omega3 fatty acids decrease the risk of arrhythmias, triglyceride levels and the growth rate of atherosclerotic plaque, and lower blood pressure slightly ${ }^{25}$.

Comparing gender differences in intake, the average daily ration was higher in men $\left(3273.6\right.$ g day $\left.^{-1}\right)$ than in women $\left(2823.8 \mathrm{~g} \mathrm{day}^{-1}\right)$. Mean energy intake was higher among men (2938.2 $\mathrm{kcalday}^{-1}$ ) compared with women (2151.4 kcalday ${ }^{-1}$ ), while the contributions of macronutrients to energy intake were similar (protein: $13.4 \%$ in women vs. $13.35 \%$ in men; carbohydrates: $47.4 \%$ in women vs. $47.1 \%$ in men; fat: $38.86 \%$ in women vs. $38.89 \%$ in men). Intakes of bread and toast, cereal and cereal products, eggs, meat and poultry, potatoes, pulses, nuts and seeds, sugar and sugar derivatives, added fats and oils, alcoholic beverages and soft drinks were significantly higher in men than women. However, intakes of milk, dairy products, vegetables and coffee were significantly higher in women. Similarly, the contribution of fruits to daily energy intake was higher among women (8.0\%) than men (5.7\%). This trend has been reported in other studies across several cultures, such as the Basque Country and Germany, where food intake was generally lower in women than in men, with the exception of vegetables, fruits, dairy products and non alcoholic beverages ${ }^{26-28}$. In the present study, the percentage of women who reported use of low-fat items was higher than that of men. This is in line with other studies reporting women as being more health-conscious and followers of dietary recommendations than men ${ }^{23,29}$.

The group aged 25-34 years had significantly higher intakes of soft drinks, pre-packed juices, sugar and sugar derivatives, and significantly lower intake of cooked vegetables, than one or both of the two older age groups. Younger men (25-34 years) consumed significantly less pulses than the group aged 35-44 years and had a significantly higher intake of alcoholic beverages than the group aged 45-54 years. This trend among younger people has been reported by other studies conducted in Spain $^{27}$ and Norway $^{23}$, and is in line with research reporting that older people are more interested in a healthy diet than younger ones ${ }^{23}$. This finding may highlight new marketing trends and consumer behaviour, which put less emphasis on fruits and vegetables and more emphasis on sugary snacks, soft drinks and alcohol.

A comparison of the mean consumption values per food group as assessed by the present survey (QFFQ), the WHO 
regional diet for the Middle East ${ }^{30}$ and the $\mathrm{HBS}^{13}$ is given in Table 6. The estimated average daily food intake excluding beverages $\left(1335 \mathrm{gday}^{-1}\right)$ in this study was similar to the WHO estimate $\left(1334 \mathrm{~g} \mathrm{day}^{-1}\right)$ and slightly lower than the $1508 \mathrm{~g} \mathrm{day}^{-1}$ reported by the HBS.

Mean consumption values of cereals and cereal-based products, potatoes and potato products, vegetables, sugar and sugar derivatives, added fat and oil were lower in the QFFQ than the $\mathrm{HBS}^{13}$ and/or WHO ${ }^{30}$ estimates. This can be attributed to the fact that waste at the household level and the actual handling of purchased items cannot be determined in household surveys, a fact which may overestimate the intake of the individual. Similarly, FBSs, on which the WHO data are based, tend to overestimate actual intake ${ }^{1}$. The observed lower intakes of sugar, fat and oil in the QFFQ may be due to the fact that the present survey estimated only the intakes of fats and oils added at the table and of fats and oils used in frying. Fats and oils used in the cooking process were treated as an inherent part of recipes. This is also applicable for sugar, which could be present as an ingredient in pastries, puddings, etc.

The respective intakes of nuts and seeds and eggs were relatively similar in all three studies. The consumption levels of fruits, meat and poultry, pulses, fish and seafood, milk and dairy products were, however, higher in the present survey compared with $\mathrm{WHO}^{30}$ data but were lower than the HBS ${ }^{13}$ data. This could be explained by the fact that the population of the present study consumes more of these products compared with other age groups, a fact that cannot appear with household surveys or foodsupply surveys since they both relate to the average individual in the population irrespective of age and gender. In addition, regional diets, such as the WHO Middle Eastern diet, are not always adaptable to countryspecific dietary patterns and thus may not always be accurate in estimating actual dietary intake. Similarly, the HBS underestimated the intake of alcoholic beverages, soft drinks and pre-packed juices because, as in Lebanon, beverages are mostly consumed outside the household.

A review of food availability as compiled by the $\mathrm{FAO}^{12}$ shows that, in the 1960s, there was heavy consumption of bread and legumes in Lebanon while consumption of red meat and poultry was rather low. In the 1960 s cereals contributed almost half of the dietary energy in urban and rural areas (49.0\%) and decreased to $36.4 \%$ in $1992^{8,31}$. The comparison of these food availability data with individual food intake data, as assessed by the present survey and by a previous dietary survey realised in 1997 (Hwalla N, unpublished data), confirm the decrease in cereal consumption and the increase in meat and poultry consumption (Table 7). Similarly, food availability data show a considerable improvement in energy and protein availability in Lebanon over the period 1960 to 1992. Total energy increased from $2396 \mathrm{kcal}_{\text {person }}{ }^{-1}$ day $^{-1}$ in the $1960 \mathrm{~s}$ to $3144 \mathrm{kcal}_{\text {person }}{ }^{-1} \mathrm{day}^{-1}$ in the $1990 \mathrm{~s}$. Total

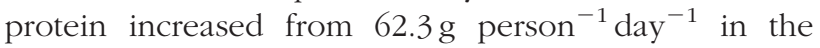
$1960 \mathrm{~s}$ to $81.2 \mathrm{~g} \mathrm{person}{ }^{-1} \mathrm{day}^{-1}$ in $1992^{12}$ up to 84.4 g person $^{-1}$ day $^{-1}$ as estimated by the present survey. Percentage of energy from fat increased from 22 to $26 \%$ during the same period and up to $38.9 \%$ as estimated by this study, which is higher than the maximum value of $30 \%$ as recommended by the $\mathrm{WHO}^{18}$. At present, the percentage contribution of cereals to daily energy has dropped and is being replaced by high-fat items: the traditional diet is eroding and is being replaced by high-fat foods ${ }^{31}$.

A comparison between food consumption patterns in the adult population of Beirut and those reported in other countries is presented in Table 8. Although the survey methodologies with which the consumption data were collected are variable between countries, food

Table 6 Comparison of food group intake $\left(\mathrm{gperson}^{-1}\right.$ day $^{-1}$ ) as estimated by the present survey (using a quantitative food-frequency questionnaire, QFFQ), the population national household budget survey (HBS) and the World Health Organization (WHO) Middle Eastern diet

\begin{tabular}{|c|c|c|c|}
\hline Food group & QFFQ & $\mathrm{HBS}^{13}$ & $\mathrm{WHO}^{30}$ \\
\hline Fruits and fruit juices & 285.5 & 328.8 & 204.4 \\
\hline Raw vegetables* and vegetable-based dishes $†$ & 245.4 & 331.0 & 233.1 \\
\hline Potatoes & 63.5 & 132.9 & 61.8 \\
\hline Pulses & 39.5 & 20.2 & 24.6 \\
\hline Nuts, seeds and olives & 12.8 & 14.2 & 12.8 \\
\hline Cereals and cereal-based products & 324.5 & 317.2 & 430.8 \\
\hline Meat and poultry & 91.7 & 117.7 & 71.3 \\
\hline Fish and seafood & 19.7 & 14.5 & 13.0 \\
\hline Milk and dairy products & 240.7 & 174.0 & $132.3 \ddagger$ \\
\hline Eggs & 12.1 & 15.3 & 14.2 \\
\hline Sugar and sugar derivatives & 33.9 & 47.9 & 95.8 \\
\hline Fats and oils & $20.4 \S$ & 43.6 & 40.3 \\
\hline Alcoholic beverages & 33.6 & 6.8 & - \\
\hline Sodas, pre-packed juices and sugary beverages & 242.1 & 137.3 & - \\
\hline Total food consumption, excluding beverages & 1335 & 1508 & 1334 \\
\hline
\end{tabular}

* The value is relative to raw vegetables. HBS and WHO data are for total vegetables without further specification on raw or cooked.

† Vegetable stews cooked with some fat or oil; may sometimes include rice.

¥ Some of the WHO values related to milk are for powdered milk, whereas the values provided by the QFFQ and HBS are relative to liquid milk.

$\S$ This value excludes oils and fats consumed with cooked dishes. 
Table 7 Trend in the contribution of various categories of foods to energy and protein supply (1961-2001)

\begin{tabular}{|c|c|c|c|c|c|c|}
\hline $\begin{array}{l}\text { Average } \\
\text { food availability }\end{array}$ & $1961-1963^{*}$ & $1971-1973^{*}$ & $1981-1983^{*}$ & $1990-1992^{*}$ & $\begin{array}{l}1997 \text { dietary } \\
\text { survey† }\end{array}$ & 2001 QFFQ \\
\hline $\begin{array}{l}\text { Energy (kcal person }{ }^{-1} \text { day }^{-1} \text { ) } \\
\text { Percentage from }\end{array}$ & 2396 & 2319 & 2844 & 3144 & - & 2523.5 \\
\hline Cereals (including bread) & 49.3 & 45.7 & 39.9 & 36.4 & 37.2 & 35.0 \\
\hline Roots and tubers & 1.3 & 1.7 & 3.2 & 3.6 & 5.0 & 6.5 \\
\hline Sugars and honey & 9.5 & 12.3 & 10.2 & 10.4 & 3.7 & 6.0 \\
\hline Pulses, nuts, oilseeds & 5.6 & 4.6 & 6.8 & 6.8 & 5.9 & 5.6 \\
\hline Fruits, vegetables & 9.6 & 9.5 & 8.8 & 14.4 & 13.9 & 9.05 \\
\hline Meat, fish, dairy, eggs & 10.9 & 11.1 & 14.4 & 10.5 & 22.6 & 21.4 \\
\hline Oils, fats & 11.3 & 12.7 & 14.4 & 15.6 & 6.4 & 6.8 \\
\hline $\begin{array}{l}\text { Protein (g person }{ }^{-1} \text { day }^{-1} \text { ) } \\
\text { Percentage from }\end{array}$ & \multicolumn{5}{|c|}{ Percentage from } & 84.4 \\
\hline Cereals (including bread) & 50.1 & 48.1 & 37.3 & 37.1 & - & 26.9 \\
\hline Roots and tubers & 0.8 & 1.1 & 1.8 & 2.2 & - & 1.5 \\
\hline Pulses, nuts, oilseeds & 9.7 & 7.9 & 13.6 & 12.6 & - & 4.0 \\
\hline Fruits, vegetables & 8.1 & 8.3 & 7.6 & 14.6 & - & 4.7 \\
\hline Meat, fish, dairy, eggs & 29.8 & 32.6 & 37.5 & 31.6 & - & 55.7 \\
\hline \multicolumn{7}{|l|}{ Percentage energy from } \\
\hline Proteins & 11 & 10 & 12 & 11 & - & 13.38 \\
\hline Fat & 22 & 23 & 27 & 26 & - & 38.88 \\
\hline
\end{tabular}

*Food availability data based on food balance sheets ${ }^{12}$.

†Food consumption data based on an individual dietary intake survey realised with a 24-hour recall (Hwalla N, unpublished data).

† Food consumption data based on an individual dietary intake survey (present study).

consumption trends could be identified ${ }^{27,32-35}$. The dietary pattern in Lebanon tends to differ from that of Egypt $^{35}$, another country of the Middle East, by higher intakes of meat and poultry, milk, dairy products and fruits. The consumption of fruits in the present study was lower than in Spain ${ }^{27,32}$, another Mediterranean country, and markedly higher than in the $\mathrm{UK}^{33}$ and the Netherlands ${ }^{34}$. The consumption of alcohol and alcoholic beverages was much lower in Lebanon compared with European countries ${ }^{32-34}$. This could be related to the fact that consumption of alcohol is forbidden in the Muslim sect.

The present study allowed the identification and quantification of the average daily intake of foods in the adult population in Beirut by means of an individual dietary survey. These dietary intake data reflect more accurately the prevailing food consumption pattern in
Lebanon than both the $\mathrm{HBS}^{13}$ and the WHO regional $\operatorname{diet}^{30}$. The rather high contribution of fat to daily energy intake, the low intake of fish and the relatively high percentage of people consuming less than the recommended amount of fruits and vegetables observed in this study suggest that the population is at increased risk of cardiovascular diseases, obesity and other NCDs, which provides the basis for recommending increased intakes of fish, particularly fatty fish, and fruits and vegetables, as well as decreased intake of fat.

The generated daily food consumption values can be used, when coupled with contaminant concentration data, in assessment of the population exposure to these compounds from the diet ${ }^{1-3}$. The data could be further used in nutritional assessment studies and may form the basis of future research into the associations between nutrients and the distribution of disease in the population.

Table 8 Comparison of the average food consumption patterns ( g person $^{-1}$ day $^{-1}$ ) in Lebanon and other countries

\begin{tabular}{|c|c|c|c|c|c|c|}
\hline Food group & $\begin{array}{l}\text { Basque } \\
\text { Country }^{27}\end{array}$ & Madrid $^{32}$ & $\mathrm{UK}^{33}$ & Netherlands ${ }^{34}$ & Egypt $^{35}$ & Lebanon* \\
\hline Meat and poultry & 163 & 145 & 150 & 111 & 37.0 & 91.7 \\
\hline Fish & 88 & 89 & 27 & 10 & 19.9 & 19.6 \\
\hline Eggs & 41 & 22 & 23 & 14 & 17.0 & 12.1 \\
\hline Milk & - & 286 & 234 & - & 31.5 & 99.7 \\
\hline Dairy products & 350 & 71 & 29 & 401 & 77.1 & 143.4 \\
\hline Pulses, nuts and seeds & 21 & 36 & 34 & 7 & 56.1 & 39.5 \\
\hline Cereals and cereal-based products & 173 & 171 & 235 & 223 & 459 & 324.5 \\
\hline Potatoes & 90 & 82 & 126 & 118 & 55.6 & 63.5 \\
\hline Vegetables & 159 & 177 & 102 & 128 & 220.4 & 146.5 \\
\hline Fruits & 345 & 290 & 73 & 114 & 18.2 & 220.5 \\
\hline Added fats and oils & 39 & 40 & 19 & 51 & 24.1 & 20.4 \\
\hline Sugar & 27 & 20 & 18 & 42 & 73.5 & 33.9 \\
\hline Alcoholic beverages & - & 172 & 302 & 157 & - & 33.6 \\
\hline
\end{tabular}


This study had, however, the following limitations: the study subjects may have under- or overreported their dietary intake $\mathrm{e}^{36}$; the seasons during which the survey took place (spring/summer) could lead to overestimation of intake of certain food items such as fruits and vegetables; also, the study population was an urban one, making the extrapolation to Lebanon rather controversial.

\section{Acknowledgements}

This study was supported by the Lebanese National Council for Scientific Research (CNRS) and by the FrenchLebanese cooperative research programme (CEDRE).

\section{References}

1 Kroes R, Muller D, Lambe J, Lowik MRH, Van Klaveren J, Kleiner J, et al. Assessment of intake from the diet. Food and Chemical Toxicology 2002; 40: 327-85.

2 Petersen BJ, Chaisson CF, Douglass JS. Use of food intake surveys to estimate exposure to nonnutrients. American Journal of Clinical Nutrition 1994; 59: 240S-4S.

3 World Health Organization (WHO). Guidelines for the Study of Dietary Intakes of Chemical Contaminants. WHO Offset Publication No. 87. Geneva: WHO, 1985.

4 Lee-Hann H, McGuire V, Boyd NF. A review of the methods used by studies of dietary measurement. Journal of Clinical Epidemiology 1989; 42: 269-79.

5 Institut Français pour la Nutrition (IFN). Abords Méthodologiques des Enquêtes de Consommation Alimentaire chez l'Homme. Dossier Scientifique No. 8. Paris: IFN, 1996.

6 Interdepartmental Committee on Nutrition for National Defense. Republic of Lebanon: Nutrition Survey (1961). Washington, DC: Government Printing Office, 1962.

7 Sabry J, Sabry Z. Nutrition in Lebanon. Canadian Nutrition 1963; 19: 121

8 Cowan JW, Chopra S, Houry G. Dietary surveys in rural Lebanon. Journal of the American Dietetic Association 1964; 30: 753-6.

9 Baba NH, Shaar K, Hamadeh S, Adra N. Nutritional status of Bedouin children aged 6-10 years in Lebanon and Syria under different nomadic pastoral systems. Ecology of Food and Nutrition 1994; 32: 247-59.

10 Baba NH, Shaar K, El Sheikh Ismail L, Adra N. Comparison of nutritional status of preschool children at day care centers and at home from different socioeconomic backgrounds in Beirut. Journal of Human Nutrition and Dietetics 1996; 9: 89-103.

11 Zein El Abidine S. Obesity and dietary habits of urban and rural populations in Lebanon. MSc thesis, American University of Beirut, Beirut, Lebanon, 1996.

12 Food and Agriculture Organization (FAO). Nutrition Country Profiles for Selected Countries of the Near East. Cairo: FAO RNE, 1995.

13 Administration Centrale de la Statistique. Conditions de Vie des Ménages en 1997. Etudes Statistiques No. 9. Beyrouth: République Libanaise, 1998.

14 First Data Bank Inc. Nutritionist Pro software, version 1.2. San Bruno, CA: First Data Bank Inc., 2002 (www.firstdatabank.com).

15 Kamal S, Osman S. Alef Baa Al Tabkh, 9th ed. Beirut: Dar Al Ilm Lil Malayeen, 1995.

16 Flegal KM, Larkin FA, Metzner HL, Thompson FE, Guire KE. Counting calories: partitioning energy intake estimates from a food frequency questionnaire. American Journal of Epidemiology 1988; 128: 749-60.

17 Flegal KM, Larkin FA. Partitioning macronutrient intake estimates from a food frequency questionnaire. American Journal of Epidemiology 1990; 131: 1046-58.

18 World Health Organization (WHO). Diet, Nutrition and the Prevention of Chronic Disease. Report of a Joint WHO/Food and Agriculture Organization Expert Consultation. WHO Technical Report Series No. 916. Geneva: WHO, 2003.

19 Briefel RR, Flegal KM, Winn DM, Loria CM, Johnson CL, Sempos CT. Assessing the nation's diet: limitations of the food frequency questionnaire. Journal of the American Dietetic Association 1992; 92: 959-62.

20 Horwath CC. Food frequency questionnaire: a review. Australian Journal of Nutrition and Dietetics 1990; 47: 71-6.

21 Hu FB. Plant-based foods and prevention of cardiovascular disease: an overview. American Journal of Clinical Nutrition 2003; 78: 544S-51S.

22 Committee on Diet and Health. Diet and Health Implications for Reducing Chronic Disease Risk. Food and Nutrition Board, Commission on Life Sciences, National Research Council. Washington, DC: National Academy Press, 1989.

23 Wandel M. Dietary intake of fruits and vegetables in Norway: influence of life phase and socio-economic factors. International Journal of Food Sciences and Nutrition 1995; 46: $291-301$.

24 American Heart Association. AHA Scientific Statement. AHA Dietary Guidelines, revision \#71-0193. Circulation 2000; 102: 2284-99.

25 Kris-Etherton PM, Harris WS, Appel LJ. Fish consumption, fish oil, omega-3 fatty acids, and cardiovascular disease. Circulation 2002; 106: 2747-57.

26 Brandstetter BR, Korfmann A, Kroke A, Becker N, Schulze MB, Boeing H. Dietary habits in the German EPIC cohorts: food group intake estimated with the food frequency questionnaire. Annals of Nutrition \& Metabolism 1999; 43: 246-57.

27 Aranceta J, Rodrigo CP, Eguileor I, Marzana I, Gonzàlez de Galdeano L, Saenz de Buruaga J. Food consumption patterns in the adult population of the Basque Country (EINUT-I). Public Health Nutrition 1998; 1: 185-92.

28 Worsley A. Cohabitation-gender effects on food consumption. International Journal of Biosocial Research 1988; 10: 107-22.

29 Fagerli RA, Wandel M. Gender differences in opinions and practices with regard to a 'healthy diet'. Appetite 1999; 32: $171-90$.

30 World Health Organization (WHO). GEMS/FOOD Regional Diets: Regional per Capita Consumption of Raw and Semi-processed Agricultural Commodities. Document WHO/FSF/FOS/98.3. Geneva: WHO, 1998.

31 Baba NH. Food consumption pattern in Lebanon. Rivisita di Antropologia 1998; 76: 193-204.

32 Aranceta J, Pérez C, Amela C, Garcia R. Encuesta de Nutricion de la Comunidad de Madrid. Documentos Tecnicos de Salud, No. 18. Direccion General de Prevencion y Promocion de la Salud. Madrid: Comunidad de Madrid, 1994.

33 Gregory J, Foster K, Tyler H, Wiseman M. The Dietary and Nutritional Survey of British Adults. London: HMSO, 1990.

34 Voorlichtingsbureau Voor de Voeding. Zo eet Nederland, 1992. Resultaten van de Voedseiconsumptiepeiling. Den Haag: Voorlichtingsbureau Voor de Voeding, 1993.

35 Saleh ZA, Brunn H, Paetzold R, Hussein L. Nutrients and chemical residues in an Egyptian total mixed diet. Food Chemistry 1998; 63: 535-41.

36 Kushi LH. Gaps in epidemiologic research methods: design considerations for studies that use food frequency questionnaires. American Journal of Clinical Nutrition 1994; 59: $180 S-4 S$. 